\title{
Biodegradation of melamine and its hydroxy derivatives by a bacterial consortium containing a novel Nocardioides species
}

\author{
Kazuhiro Takagi • Kunihiko Fujii • Ken-ichi Yamazaki • \\ Naoki Harada • Akio Iwasaki
}

Received: 5 August 2011 /Revised: 9 October 2011 / Accepted: 26 October 2011 /Published online: 22 November 2011

(C) Springer-Verlag 2011

\begin{abstract}
Melamine has recently been recognized as a food contaminant with adverse human health effects. Melamine contamination in some crops arises from soil and water pollution from various causes. To remove melamine from the polluted environment, a novel bacterium, Nocardioides sp. strain ATD6, capable of degrading melamine was enriched and isolated from a paddy soil sample. The enrichment culture was performed by the soil-charcoal perfusion method in the presence of triazine-degrading
\end{abstract}

Kunihiko Fujii contributed equally to this work as the first author.

K. Takagi $\cdot$ K. Yamazaki

Organochemicals Division,

National Institute for Agro-Environmental Sciences,

3-1-3 Kannondai,

Tsukuba, Ibaraki 305-8604, Japan

K. Fujii $(\varangle) \cdot$ N. Harada $\cdot$ A. Iwasaki

Kowa Research Institute, Kowa Co., Ltd,

1-25-5 Kannondai,

Tsukuba, Ibaraki 305-0856, Japan

e-mail: ku-fujii@ccr.niigata-u.ac.jp

Present Address:

K. Fujii

Office for Environment and Safety, Niigata University,

2-8050 Ikarashi, Nishi-ku,

Niigata 950-2181, Japan

Present Address:

N. Harada

Faculty of Agriculture, Niigata University,

2-8050 Ikarashi, Nishi-ku,

Niigata 950-2181, Japan

Present Address:

A. Iwasaki

Department of Intellectual Property, Kowa Co., Ltd,

3-4-14 Nihonbashi-Honcho, Chuo-ku,

Tokyo 103-8433, Japan bacteria previously obtained. Strain ATD6 degraded melamine and accumulated cyanuric acid and ammonium, via the intermediates ammeline and ammelide. No gene known to encode for triazine-degrading enzymes was detected in strain ATD6. A mixed culture of strain ATD6 and a simazine-degrading Methyloversatilis sp. strain CDB21 completely degraded melamine, but the degradation rate of cyanuric acid was slow. The degradation of melamine and its catabolites by the mixed culture was greatly enhanced by including Bradyrhizobium japonicum strain CSB1 in the inoculum and adding ethanol to the culture medium. The melamine-degrading consortium consisting of strains ATD6, CDB21, and CSB1 appears to be potentially safer than other known melamine-degrading bacteria for the bioremediation of farmland and other contaminated sites, as no known pathogens were included in the consortium.

Keywords Melamine - Cyanuric acid B Biodegradation . Nocardioides $s p$. Bacterial consortium

\section{Introduction}

Melamine (1, 3, 5-triazine-2, 4, 6-triamine) is a member of the $s$-triazine family and is synthesized on a large scale as an industrial component in melamine formaldehyde resin, which is used to make a wide variety of plastic goods, laminates, and coatings. For many years, melamine was considered to be a harmless substance unless administered as a large dose orally or intravenously (Lipschitz and Stokey 1945). However, this opinion of melamine changed after a large outbreak of nephrotoxic renal failure of dogs and cats associated with the intake of melaminecontaminated pet foods occurred in 2007 in North America (Brown et al. 2007), and four thousand dogs and cats died 
from acute renal failure. Melamine and its hydroxyl analogues such as ammeline (4,6-diamino-2-hydroxy1,3,5-triazine), ammelide (6-amino-2,4-dihydroxy-1,3,5triazine), and cyanuric acid (1,3,5-triazinane-2,4,6-trione) were detected in vegetable proteins in the contaminated pet foods (Dobson et al. 2008). Chemical analysis of crystals found in the kidney tubules of the dead animals identified that they were mainly composed of co-crystallized melamine and cyanuric acid, both of which were present in extremely high concentrations (more than $3,000 \mathrm{mg} \mathrm{kg}^{-1}$ ) in vegetable proteins produced in China (Suchý et al. 2009).

In 2008, an outbreak of stones (calculi) of the urinary system and renal failure in infants occurred in China due to intake of melamine-contaminated milk formula. The Chinese Ministry of Health reported that 294,000 infants had been affected, with 50,000 hospitalized, and 6 dead by the end of November 2008 (WHO 2009). In contrast to the animal cases in the USA, the calculi in the Chinese infants were composed of melamine and uric acid in all patients investigated, and no cyanuric acid was identified (Sun et al. 2010). Melamine was intentionally added to the milk to elevate the apparent protein content, and the maximum concentration detected in the contaminated milk formula was 2,563 $\mathrm{mg} \mathrm{kg}^{-1}$ (Liu et al. 2010). Many countries have since introduced limits for melamine in powdered infant formula $\left(1 \mathrm{mg} \mathrm{kg}^{-1}\right)$ and other foods $\left(2.5 \mathrm{mg} \mathrm{kg}^{-1}\right)$ (WHO 2009).

Qin et al. (2010) assessed melamine contamination levels in 557 crop samples collected from various provinces in China. Low-level (less than $400 \mu \mathrm{g} \mathrm{kg}^{-1}$ ) contamination with melamine was detected in most crops. Concentrations at levels of the food contamination limit for melamine were detected in three crops $\left(1.13-2.05 \mathrm{mg} \mathrm{kg}^{-1}\right)$. Melamine contamination was also detected in farmland soil samples and irrigation waste, and higher levels of melamine contamination were observed in the wastewater and soil around melamine factories. However, the relationship between melamine concentrations in crop and environment samples has not been reported.

Lim et al. (1990) and Sancho et al. (2005) showed that the melamine found in crops was a metabolite of a triazine pesticide, cyromazine. In cyromazine application trials, increasing amounts of residual melamine were detected in crop samples with elevated application rates of the pesticide. Cyromazine has also been used for the control of fly larva in poultry manure. Melamine has been detected in soil treated with cyromazine-containing poultry manure as a fertilizer and in crops planted in the soil (FAO/WHO 2008).

Melamine itself has been repeatedly investigated as fertilizer. Scholl et al. (1937) synthesized melamine from dicyanodiamide, a derivative of cyanamide, and examined its value as a fertilizer for millet. However, melamine was less effective than sodium nitrate, ammonium sulfate, urea, and calcium cyanamide. The nitrogen from melamine was the least available of any nitrogenous fertilizer examined for improving the yields of corn and Bermuda grass (Terman et al. 1964). Wehner and Martin (1989) evaluated melamine in combination with urea as a slow-release nitrogen fertilizer for lawn care. Compared with urea alone, the turf grass response from the combined melamine fertilizer application showed no significant residual response as a slow-release fertilizer. The low $\mathrm{N}$ availability from melamine for plants is attributed to its slow degradation rate in soil and low water solubility leading to melamine contamination of farmland soil and crops.

The need for a cleanup technology for residual melamine in polluted farmland soil has increased after the melaminecontaminated food incidents described above. Considering the difficulties associated with the application of remediation technologies to farmland, a bioremediation technique is the most promising, effective, and safer way to remove residual melamine from soil.

In our laboratory, a series of $s$-triazine-degrading bacteria were isolated, including: a simazine-degrading Methyloversatilis sp. strain CDB21; a simetryn-degrading Rhodococcus sp. strain FJ1117YT; and a wide ranging $s$-triazine-degrading Nocardioides sp. strain MTD22 (Iwasaki et al. 2007; Fujii et al. 2007; Yamazaki et al. 2008a). Strain CDB21 holds genes atzs $A, B, C, D, E$, and $F$ which encode for the atrazinecatabolizing enzymes, atrazine chlorohydrolase (AtzA); hydroxyatrazine $n$-ethylaminohydrolase (AtzB); $n$ isopropylammelide aminohydrolase (AtzC); cyanuric acid amidohydrolase (AtzD); biuret hydrolase (AtzE); and allophanate hydrolase (AtzF). Strain FJ1117YT uses an unknown mechanism for degrading $s$-triazine compounds. Strain MTD22 carries the gene $\operatorname{trz} N$ for triazine hydrolase (TrzN), as well as $a t z B$ and $a t z C$. A preliminary study showed that melamine degradation by these bacterial strains was unsuccessful.

Several melamine-degrading bacteria have been reported. Pseudomonas sp. strain A (NRRL B-12227) was isolated as a melamine-utilizing bacterium from municipal sewage collected in Switzerland (Cook and Hütter 1981; Cook 1987) and was later reclassified as Acidovorax citrulli (Seffernick et al. 2002; Schaad et al. 2008). Another melamine-degrading isolate, Rhodococcus corallinus strain 11 (NRRL B-15444R), was obtained from soils that had been experimentally exposed to $s$-triazine herbicides for a long time (Cook and Hütter 1984; Cook 1987). $R$. corallinus was originally considered to be a junior synonym of Rhodococcus rubropertinctus in a DNA homology study (Mordarski et al. 1980), and has since been reclassified as Gordonia rubripertincta (Stackebrandt et al. 1988; Euzeby 1998). Genes encoding enzymes for 
melamine deamination, $\operatorname{trz} A$ for $s$-triazine hydrolase (TrzA) and triA for melamine deaminase (TriA), were cloned from G. rubripertincta strain NRRL B-15444R and A. citrulli strain NRRL B-12227, respectively (Shao et al. 1995; Seffernick et al. 2001). Shelton et al. (1997) determined the melamine metabolism pathway used by Klebsiella terragena strain DRS-1, isolated from sewage sludge enrichments (Hapeman et al. 1995). Micrococcus sp. strain MF-1 mineralized the melamine formaldehyde that is found with melamine as an intermediate metabolite (El-Sayed et al. 2006) and was isolated from wastewater from an aminoplastic plant.

There are some special safety considerations when applying microorganisms to melamine-contaminated farmland, as some of the melamine-degrading bacteria described above have problems associated with their safe use in crop fields. A. citrulli is known to be a serious plant pathogen for watermelon (Schaad et al. 2008). An attempt to enhance turf quality, which had previously been lowered by melamine fertilizer, using an inoculant containing $A$. citrulli strain NRRL B-12227 (reported as Pseudomonas strain NRRL 12226) failed, and the turf quality actually declined as the rate of inoculation increased (Peacock and Dipaola 1992). Opportunistic lung infections caused by G. rubripertincta have been reported by Hart et al. (1988) and Osoagbaka (1989). The genus Klebsiella includes an important pathogen Klebsiella pneumoniae, although the phylogenetic affiliation of $K$. terragena strain DRS-1 in the genus has not yet been published. Infections caused by Micrococcus species are very rare but are reported to be common in patients with pulmonary hypertension on continuous prostacyclin (epoprostenol) infusion through a catheter (Valdivia-Arenas and Sood 2008). Thus, none of the known melamine-degrading bacterial strains are suitable for use as a bioremediation inoculum for contaminated sites, especially in farmland.

In this study, the enrichment and isolation of a novel melamine-degrading Nocardioides species from farmland soil are described. The nonpathogenic properties of the genus Nocardioides and usefulness of the isolate in the safe bioremediation of melamine-contaminated farmland soil will be discussed. The melamine metabolism pathway and complete degradation of melamine by a bacterial consortium including the isolated strain are also examined.

\section{Materials and methods}

Chemicals and media

Melamine and cyanuric acid were purchased from Junsei Chemicals (Tokyo, Japan) and Kanto Chemicals (Tokyo, Japan), respectively. Ammeline and ammelide were pur- chased from Tokyo Chemical Industry (Tokyo, Japan). Difco $^{\mathrm{TM}}$ R2A agar medium was purchased from Becton, Dickinson and Company (NJ, USA). All other chemicals were obtained from Wako Pure Chemical Industries (Osaka, Japan).

In this study, a low concentration mineral salt medium (LMM) was used for all liquid cultures. The LMM was prepared as follows: after autoclaving, $1 \mathrm{~L}$ of milli-Q water, $10 \mathrm{~mL}$ of phosphate mixture $\left(6.5 \mathrm{gL}^{-1} \mathrm{~K}_{2} \mathrm{HPO}_{4}\right.$ and $1.7 \mathrm{gL}^{-1}$ $\mathrm{KH}_{2} \mathrm{PO}_{4}$ ), and $10 \mathrm{~mL}$ of a trace element solution (Yanze-kontchou and Gschwind 1994) were mixed.

Melamine and cyanuric acid were dissolved by heating at $70^{\circ} \mathrm{C}$ in LMM or milli-Q water (for the standard solution) and then sterilized by filtration. Fifty milligrams of ammeline or ammelide was dissolved by heating at $95^{\circ} \mathrm{C}$ for $1.5 \mathrm{~h}$ in $1 \mathrm{~L}$ of $1 \%$ phosphoric acid. The standard solutions of these chemicals were made up to $1 \mathrm{~L}$ and then diluted to form $5 \mathrm{mg} \mathrm{L}^{-1}$ solutions with milli-Q water.

Analysis of melamine and its catabolites

The concentrations of melamine, ammeline, ammelide, and cyanuric acid were measured by hydrophilic interaction chromatography (HILIC). The instrumentation consisted of an in-line degasser, a 600E pump, a 717 autosampler, a column oven, and a 486 diode array detector (Waters Corporation, MA, USA), and the peak resolution was performed with an HILIC column (TSK-gel Amide-80, 4.6 i.d. $\times 250 \mathrm{~mm}, 5 \mu \mathrm{m}$ particle size, Tosoh Corporation, Tokyo, Japan) at $40^{\circ} \mathrm{C}$. The mobile phase was $23 \% 5 \mathrm{mM}$ phosphate buffer (prepared from 2 parts $5 \mathrm{mM} \mathrm{NaH} \mathrm{NO}_{4}$ and 1 part $5 \mathrm{mM} \mathrm{Na}_{2} \mathrm{HPO}_{4}$, pH adjusted to 6.7) and $77 \%$ acetonitrile, with a flow rate of $1 \mathrm{~mL} \mathrm{~min}{ }^{-1}$. The detection was based on ultraviolet (UV) absorption at $213 \mathrm{~nm}$. The UV chromatograms were logged and integrated using the EZChrom Elite Client/Server software (version 2.8.3, Scientific Software inc., CA, USA). Quantification was carried out by the external standard method based on UV peak areas.

Analysis of ammonium

Analysis of the ammonium ion was carried out by ion chromatography (Tosoh IC-2001, Tosoh Corporation, Tokyo, Japan). The separation column was a TSKgel super IC-CR column $(4.6 \mathrm{~mm}$ i.d. $\times 150 \mathrm{~mm}$, Tosoh) connected to a TSK Super IC-CR guard column $(4.6 \mathrm{~mm}$ i.d. $\times 10 \mathrm{~mm})$, and the mobile phase was an aqueous solution of $2.2 \mathrm{mM}$ methanesulfonic acid and $1.0 \mathrm{mM} 18$-crown- 6 . The column temperature was set at $40^{\circ} \mathrm{C}$, and the mobile phase flow rate was $0.7 \mathrm{~mL} \mathrm{~min}^{-1}$. Detection was carried out with electrical conductivity detector, and the concentration of ammonium ion was calculated using IC workstation (an accessory program of IC-2001, Tosoh, Japan). 
Enrichment and isolation of the melamine-degrading bacterium

The enrichment culture of the melamine-degrading bacteria was performed by the soil-charcoal perfusion method (Iwasaki et al. 2007; Takagi et al. 2009). A paddy soil from Joso City (Ibaraki, Japan) was used as the source of the microorganisms. One gram of the soil was mixed with $3 \mathrm{~g}$ of charcoal A100 (provided by Toyo Denka Kogyo, Kochi, Japan) and set in a perfusion apparatus as described by Audus (1946). A $10-\mu \mathrm{L}$ loop of $s$-triazine-degrading bacteria previously isolated in our laboratory, including strain CDB21 (Iwasaki et al. 2007), strain FJ1117YT (Fujii et al. 2007), and strain MTD22 (Yamazaki et al. 2008a), were inoculated into the perfusion apparatus. Bacteria accompanying the $s$-triazine-degrading strains, Bradyrhizobium japonicum strain CSB1 (isolated with strain CDB21, Yamazaki et al. 2008b) and Hyphomicrobium sp. strain S (isolated with strain MTD22, data not shown), were also included in the inoculum. Prior to the inoculation, these bacteria had been incubated on R2A agar medium at $30^{\circ} \mathrm{C}$ for 4-7 days. The details of the perfusion and operating conditions of the apparatus are described in previous reports (Iwasaki et al. 2007; Fujii et al. 2007).

After the enrichment had been completed, $1 \mathrm{~mL}$ aliquots of the perfusion fluid were harvested and inoculated into $100 \mathrm{~mL}$ Erlenmeyer flasks containing $20 \mathrm{~mL}$ LMM supplemented with $20 \mathrm{mg} \mathrm{L}^{-1}$ melamine. The flasks were shaken at $210 \mathrm{rpm}$ at $30^{\circ} \mathrm{C}$ on a rotary shaker, and the melamine concentration was measured periodically. The flask culture was subsequently subcultured using the limiting dilution culture method. Three subculture trials were conducted in flask cultures containing 11, 36, and $51 \mathrm{mg} \mathrm{L}{ }^{-1}$ melamine. The final subculture fluid was harvested and diluted. One hundred microliters of the diluent was spread on R2A agar medium and incubated at $30^{\circ} \mathrm{C}$ for 2 days. The colonies formed on the agar medium were isolated, and their melamine degradation abilities were confirmed in LMM containing $40 \mathrm{mg} \mathrm{L}^{-1}$ melamine.

\section{Identification of the isolated bacteria}

The morphological and physiological characterization of the isolated strain was performed by the TechnoSuruga Laboratory Co., Ltd. (Shizuoka, Japan). The total DNA of the isolate was purified using a DNeasy Blood and Tissue Kit (QIAGEN, Hilden, Germany). The 16S rRNA gene was amplified by PCR using the known primers fD1, fD2, and rD1 (Fujii et al. 2007). The PCR was processed on a thermal cycler GeneAmp PCR System 9700 (Applied Biosystems, CA, USA) with the following program: 1 cycle of $10 \mathrm{~min}$ at $95^{\circ} \mathrm{C} ; 30$ cycles of $30 \mathrm{~s}$ at $95^{\circ} \mathrm{C}, 30 \mathrm{~s}$ at $60^{\circ} \mathrm{C}$ and $1 \mathrm{~min}$ at $72^{\circ} \mathrm{C}$; and 1 cycle of $7 \mathrm{~min}$ at $72^{\circ} \mathrm{C}$. The
PCR products were purified using a QIAquick PCR Purification Kit (QIAGEN). The cycle sequencing reactions were then performed using a Thermo Sequenase Primer Cycle Sequencing Kit (GE Healthcare UK Ltd., Buckinghamshire, UK) with the following 5'-Texas Red-labeled primers: fD1, 341f, 534r, 907fT, 907rA, 1223r, and rP1 (Yamazaki et al. 2008a). The PCR products were then analyzed using a SQ5500E DNA Sequencer (Hitachi Ltd., Tokyo, Japan). A homology search of $16 \mathrm{~S}$ rRNA gene sequences was performed with the GENETYX-PDB software (version 4.0, Genetyx Corporation, Tokyo, Japan) using the FASTA and BLAST search engines with the bacterial sequences in the GenBank database. Regions of unaligned nucleotides were manually removed. A phylogenetic dendrogram was constructed using the neighborjoining method with ClustalX (version 2.0.9) and njplot (version 2.1) (Thompson et al. 1997).

Detection of genes encoding $s$-triazine-degrading enzymes

The PCR detection of genes encoding for $s$-triazinedegrading enzymes ( $a t z \mathrm{~s} A, B, C, D, E, F$, and $\operatorname{tr} z N$ ) in the melamine-degrading isolate was performed using specific primers, as described previously (Yamazaki et al. 2008a) with a slight modification to the primer pair for amplifying $a t z D$. The primers for $a t z D$ were atzDf2 (5'-TCCCACCT GACATCACAAAC-3') and atzDr2 (5'-GGGTCTCGAG GATTTGATTG.-3'). The sequence of the gene triA was 98\% identical to $a t z A$ (Seffernick et al. 2001), so the primer pairs for $a t z A$ are also available to detect triA. To detect the $\operatorname{trz} A$ gene (Shao et al. 1995), a pair of primers, trzA1f ( $5^{\prime}-$ GACCAGAATCGCAATCACC-3') and trzA1r (5'TACAGCAGTGTTCCGACTC-3'), are used. The primer pairs used for amplifying $t r z C$-encoding ammelide aminohydrolase (TrzC) (Eaton and Karns 1991), trzD-encoding cyanuric acid amidohydrolase (TrzD) (Karns 1999), and trzF-encoding allophanate hydrolase (TrzF) (Shapir et al. 2006) were trzCf (5'-GGTAGAGCCTCACATCCATC-3') and $\operatorname{trzCr}$ (5'-GAGCCAAACATTACGGAGAC-3'), trzDf (5'-CCTCGCGTTCAAGGTCTACT-3') and trzDr (5'TCGAAGCGATAACTGCATTG-3'), and trzFf (5'GAAAAGCCAGAGGTGAGGAG-3') and trzFr (5'ACCTGCCGTGAGAATGAGTC-3'), respectively. The PCR conditions are described above.

Batch culture experiment

Twenty milliliters of LMM supplemented with $39.6 \mu \mathrm{M}$ (5 $\mathrm{mg} \mathrm{L}^{-1}$ ) melamine was poured into sterilized $100 \mathrm{~mL}$ Erlenmeyer flasks. To examine the effect of different carbon sources, sterilized carbon source stock solutions were filtered and added with $317.2 \mu \mathrm{M}\left(40 \mathrm{mg} \mathrm{L} \mathrm{L}^{-1}\right)$ melamine to the LMM. The cells of bacteria incubated on 


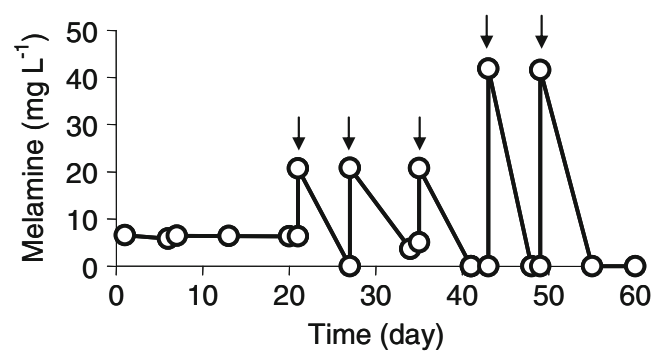

Fig. 1 Change in melamine concentration during the enrichment of the melamine-degrading bacteria with a soil-charcoal perfusion apparatus. Arrows indicate the replacement of perfusion fluid with LMM supplemented with melamines

an R2A agar plate at $30^{\circ} \mathrm{C}$ for 4-7 days were suspended in the LMM, and each bacterial suspension was then inoculated into a flask. The initial optical density of each individual bacterial inoculant at $600 \mathrm{~nm}\left(\mathrm{~A}_{600}\right)$ was adjusted to about 0.05 . To examine the effect of ethanol on the degradation of melamine and cyanuric acid, a filtersterilized aqueous solution of ethanol was added to the medium. The cultivation was carried out at $210 \mathrm{rpm}$ at $30^{\circ}$ $\mathrm{C}$ on a rotary shaker. Aliquots of the culture fluid $(1 \mathrm{~mL})$ were periodically harvested in $1.5-\mathrm{mL}$ microtubes and centrifuged at $19,000 \times g$ for $5 \mathrm{~min}$. The residual $s$-triazine concentration in the supernatant was analyzed by HILIC, and the ammonium ion concentration was measured by ion chromatography.

\section{Results}

Enrichment and isolation of strain ATD6

No change in the melamine concentration was observed during the initial perfusion trial with $6.6 \mathrm{mg} \mathrm{L}^{-1}$ melamine for 3 weeks. Melamine degradation was observed after the first replacement of the perfusion fluid to fresh one containing $20 \mathrm{mg} \mathrm{L}^{-1}$ melamine (Fig. 1). The melamine degradation ability of the perfusion culture was maintained in the following perfusion fluid replacements until after the fifth trial with an elevated melamine concentration of $40 \mathrm{mg} \mathrm{L}^{-1}$. An aliquot of the perfusion fluid was harvested at the end of the fourth trial (after 43 days from the start of perfusion) and transferred to a flask culture. After melamine degradation had been detected, the 8-day culture fluid was diluted in a tenfold serial dilution and subcultured. Melamine degradation was found in the $10^{0}-10^{-5}$-fold serial dilution cultures within 10 days of cultivation. The $10^{-5}$-fold dilution culture was subcultured twice in the same manner with an elevated concentration of melamine. Melamine degradation of the final subculture was detected after 4 days of cultivation. The $10^{-4}$-fold final subculture was transferred to an R2A agar medium. Fifteen colonies that appeared on the agar plate were isolated and subjected to a flask culture for 11 days. Melamine degradation by a certain isolate was confirmed, and a melamine-degrading bacterium was further purified from the isolate and named strain ATD6.
Fig. 2 Phylogenetic affiliation of strain ATD6 based on the 16S rRNA sequence data, showing the relationship to representative species in the genus Nocardioides. GenBank accession numbers are provided in parenthesis. The numbers at the branch points are bootstrap values based on 1,000 trials. Species of the genus Aeromicrobium in the family Nocarioidaceae are also shown. The Rhodococcus globerurus sequence was used as an outgroup. Bar indicates ten nucleotide substitutions per 1,000 nucleotide positions

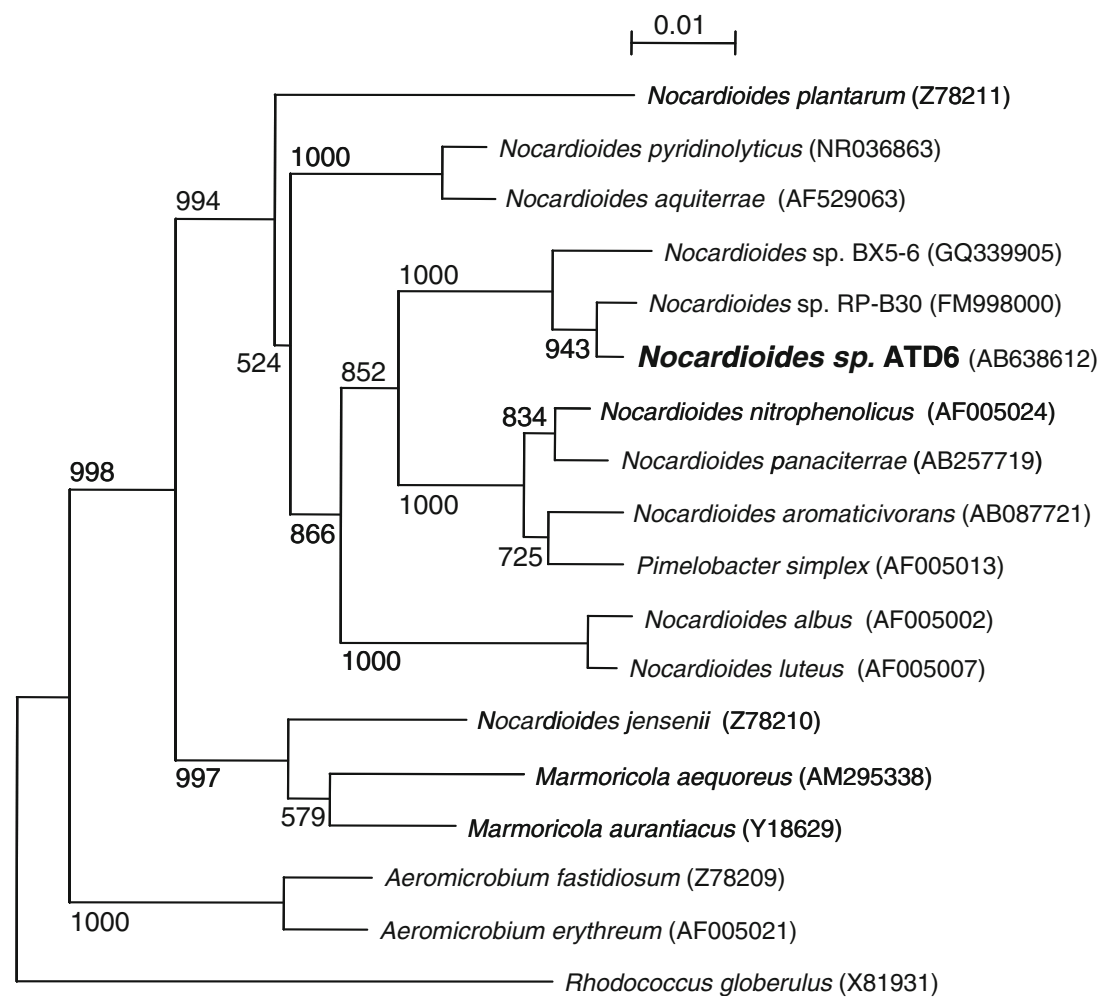


Identification of strain ATD6

Strain ATD6 was a Gram-positive (including Gramvariable), catalase-positive, oxidase-negative, nonmotile, nonspore-forming, and pleomorphic rod-shaped bacterium that forms cream colored circular colonies on the R2A agar medium. The cell size is $0.8-1.0 \mu \mathrm{m} \times 2.0-4.0 \mu \mathrm{m}$. These results suggest that the bacterium belongs to the coryneform group. Comparison of the 16S rRNA genes of strain ATD6 (1,474 bp, GenBank ID: AB638612) with the sequences available in the GenBank database showed a $99.2 \%$ identity with Nocardioides sp. strain RP-B30 (GenBank ID: FM998000) and $98.3 \%$ with Nocardioides sp. strain BX5-6 (GenBank ID: GQ339905). Close relationships were also seen with a group including Nocardioides nitrophenolicus (GenBank ID: AF005024) (Yoon
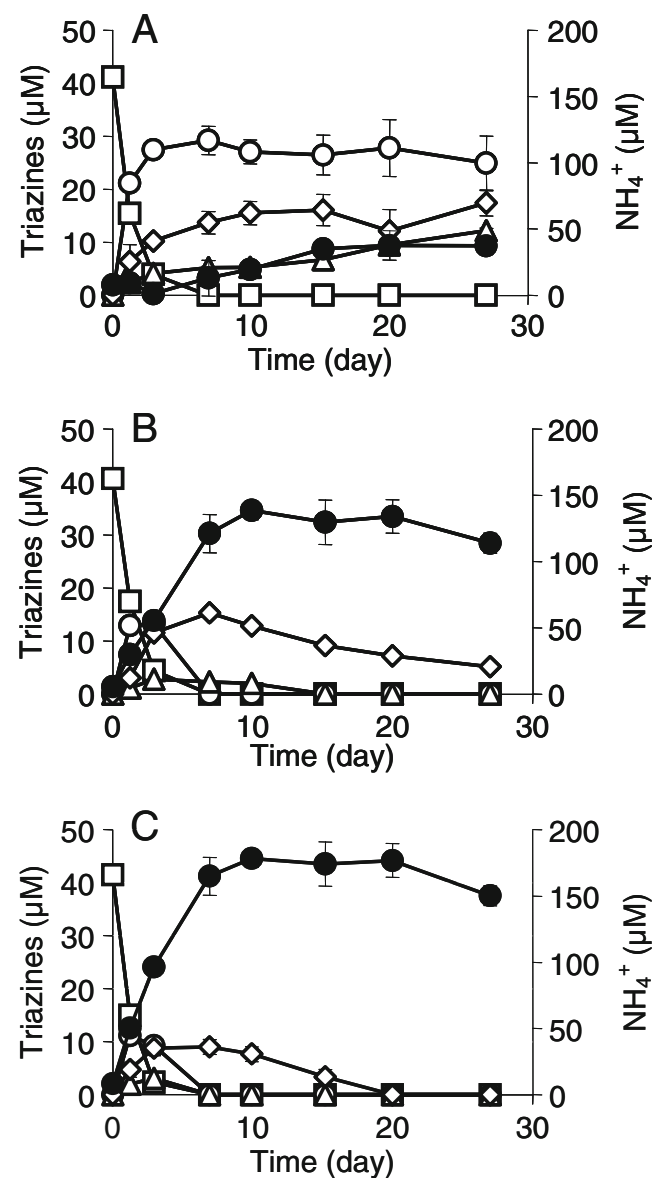

Fig. 3 Degradation of melamine by strains ATD6 (a), ATD6 + CDB21 (b), and ATD6 + CDB21 + CSB1 (c) in LMM. Changes in the concentrations of melamine (open square), ammeline (open circle), ammelide (open triangle), cyanuric acid (open diamond), and ammonium (closed circle) are shown as the mean value of triplicate experiments. Error bars indicate standard deviations et al. 1999) and Pimerobacter (Nocardioides) simplex (GenBank ID: AF005013) (Yoon et al. 1998) (sequence identity values of $96.4 \%$ and $96.1 \%$, respectively) and are shown in a phylogenetic dendrogram (Fig. 2). Strain ATD6 was assigned to a novel species in the genus Nocardioides (Prauser 1976) based on these results. Strain ATD6 was deposited at the National Institute of Agrobiological Sciences Genebank, Ibaraki, Japan (MAFF 211978) together with strains CDB21 (MAFF 211980) and CSB1 (MAFF 211979).

Degradation of melamine by strain ATD6

Batch culture experiments were performed to examine the ability of strain ATD6 as a melamine-degrading inoculum in LMM. The rapid disappearance of melamine and formation of ammeline were observed (Fig. 3a). The concentration of the generated ammeline slowly decreased even after melamine had been completely degraded, and cyanuric acid gradually accumulated. Ammelide was also formed, but its concentration remained at a lower level than the ammeline and cyanuric acid. The gradual release of ammonium, along with the degradation of melamine and its intermediates, was also detected.

PCR detection of genes that encode known s-triazinedegrading enzymes in strain ATD6 was all negative (data not shown). The genes responsible for the initial melamine deamination $\operatorname{trz} A$ and triA were also not detected in strain ATD6.

Degradation of melamine by bacterial consortium

When strain ATD6 was used as the sole inoculant, the accumulation of cyanuric acid was observed with the degradation of melamine (Fig. 3a). To completely decompose the melamine, a batch co-culture of strain ATD6 and strain $\mathrm{CDB} 21$, which has the $a t z D, E$, and $F$ genes for catabolizing cyanuric acid (Martinez et al. 2001), was examined. The co-culture degraded melamine more rapidly than strain ATD6 alone. Ammeline was formed, but soon disappeared (Fig. 3b), and small amounts of ammelide were also detected until the tenth day from the start of cultivation. The degradation of cyanuric acid became apparent after the seventh day but was not complete even at the end of the experiment. More than $3 \mathrm{~mol}$ of ammonium were generated from $1 \mathrm{~mol}$ of melamine.

To improve the overall degradation rate, melamine degradation by another bacterial consortium consisting of strains ATD6, CDB21, and CSB1 was carried out. Strains CSB1 and CDB21 comprise the simazine-degrading bacterial consortium CD7 (Yamazaki et al. 2008b). Degradation of the intermediates ammeline, ammelide, and cyanuric 

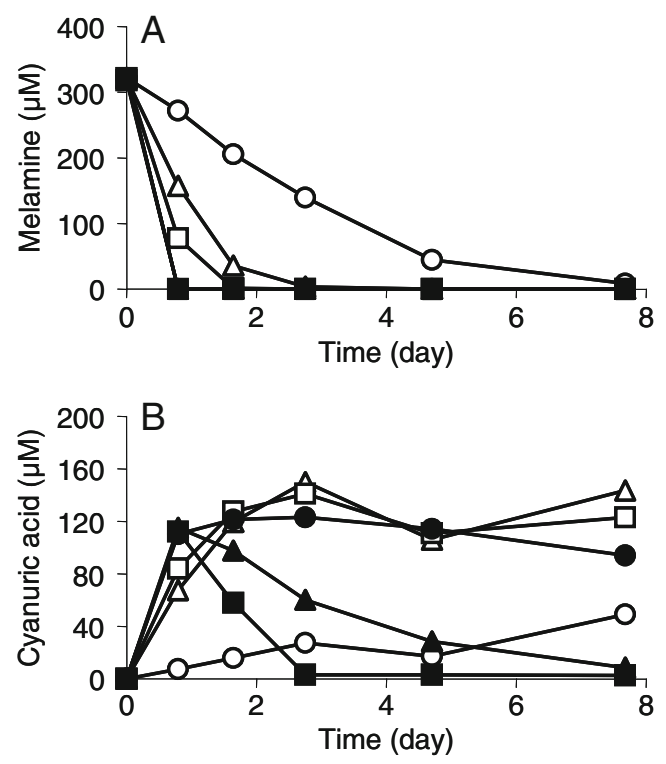

Fig. 4 Evaluation of the effect of ethanol concentration on the degradation of melamine and cyanuric acid by the three-membered consortium in LMM. Changes in the concentrations of melamine (a) and cyanuric acid (b) by the consortium of strains ATD6, CDB21, and CSB1 in the presence of 0 (open circle), 16.2 (open triangle), 32.4 (open square), 64.7 (closed circle), 129 (closed triangle), and 259 (closed square) $\mu \mathrm{M}$ ethanol are shown as the mean value of duplicate experiments

acid by the three-membered consortium was faster than by the two-membered co-culture (Fig. 3b, c). Ammeline and ammelide were barely detected after 7 days, and cyanuric acid was completely degraded after 20 days. The generation of the ammonium was increased (Fig. 3c).

Effect of ethanol on degradation of melamine and its catabolites

Even with the three-membered consortium, the rate of cyanuric acid degradation was still slow in LMM (Fig. 3c). The effect of different carbon sources on the degradation of cyanuric acid by strain CDB21 was initially investigated using methanol, ethanol, sodium acetate, sodium pyruvate, tartalic acid, glucose, and sodium citrate. Cyanuric acid degradation was observed when ethanol and methanol were used as a carbon source, and ethanol resulted in more rapid degradation (data not shown). The degradation of $317.2 \mu \mathrm{M}$ of melamine and the change in cyanuric acid concentration by the three-membered consortium were examined in the presence of various ethanol concentrations.

Almost all of the melamine was degraded, and the slow accumulation of cyanuric acid was observed after 8 days of cultivation in the absence of ethanol. The degradation of melamine and generation of cyanuric acid were enhanced as ethanol concentration increased (Fig. 4). Melamine was completely degraded within 1 day when the LMM was supplemented with more than $64.7 \mu \mathrm{M}$ ethanol (Fig. 4a). The amount of cyanuric acid generated gradually decreased as the amount of ethanol increased, with the apparent degradation of cyanuric acid occurring in the presence of $129 \mu \mathrm{M}$ ethanol, and the complete degradation of cyanuric acid in the presence of $259 \mu \mathrm{M}$ ethanol (Fig. 4b). Similar enhancements to changes in the ammeline and ammelide concentrations were also observed (data not shown). No further acceleration of the degradation rate was observed beyond $518 \mu \mathrm{M}$ ethanol. The growth of the bacteria was accelerated with the increasing ethanol concentrations (data not shown).

\section{Discussion}

The soil-charcoal perfusion method used in this study is an outstanding tool for enriching and isolating chemical contaminant-degrading microorganisms for bioremediation application. In our previous study, three strains of $s$-triazine-degrading bacteria were isolated by this method. Methyloversatilis sp. strain CDB21 was able to completely degrade simazine (Iwasaki et al. 2007). Rhodococcus sp. strain FJ1117YT transformed methylthio-s-triazines into 2-hydroxy derivatives via sulfur oxidation (Fujii et al. 2007). Nocardioides sp. strain MTD22 was capable of decomposing a wide range of $s$-triazine herbicides and accumulating cyanuric acid (Yamazaki et al. 2008a). Incomplete $s$-triazine-degrading bacteria, such as strain FJ1117YT, often require co-culturing with other degrading bacteria and/or some accompanying bacteria to complete the degradation and utilization of $s$-triazine compounds for their growth (Yamazaki et al. 2008b). The enrichment culture in the current study was, therefore, conducted in the presence of $s$-triazine-degrading bacterial consortia in expectation of their supporting roles in melamine degradation. Consequently, melamine degradation was detected soon after the first exchange of the perfusion fluid (Fig. 1). Isolation of the melamine-degrading strain ATD6 was then achieved with the 43-day perfusion fluid.

Strain ATD6 was identified as a novel Nocardioides species. The phylogenetic dendrogram indicates that strain ATD6 constitutes a new group in the genus together with new strains RP-B30 (GenBank ID:FM998000) and BX5-6 (GenBank ID:GQ339905) (Fig. 2). These new strains were isolated from the rhizosphere soil of a plant (Peucedanum japonicum Thunb.) and a field soil in Korea, respectively, but have not yet been published. Strain ATD6 is the first melamine-degrading Nocardioides species to the best of our knowledge.

The pattern of the appearance of intermediates in the LMM batch culture of strain ATD6 indicates that melamine was deaminated in a sequential manner. Although the rapid 
degradation of melamine was observed, the degradation rates of the intermediates were slow, and cyanuric acid accumulated as the end product (Fig. 3a). In this situation, co-culturing with bacteria capable of degrading intermediates, such as strain CDB21, is effective for faster and complete degradation (Yamazaki et al. 2008b). The coculture with strains ATD6 and CDB21 further degraded cyanuric acid as expected (Fig. 3b).

Strain CDB21 contains the genes atzs $A, B, C, D, E$, and $F$ which encode for atrazine-catabolizing enzymes (Iwasaki et al. 2007). It was expected that the cyanuric acid accumulated by strain ATD6 would be mineralized by the action of the catabolic enzymes AtzsD, E, and F from strain CDB21. The partial mineralization of melamine was demonstrated by the generation of ammonium in an approximate 4:1 molar ratio to the initial concentration of melamine after 7 days of culture by the three-membered consortium (Fig. 3c). The generation of between 3 and 6 mol of ammonium appears to indicate that some nitrogen atoms from the $s$-triazine ring in melamine are converted to ammonium, and some are assumed to be incorporated in the bacterial cells.

Ammelide is utilized as a substrate for AtzC (Shapir et al. 2002). Strain CDB21, which has gene $a t z C$, was able to enhance ammelide degradation in the two-membered co-culture. The co-culture also appeared to accelerate ammeline degradation. Seffernick et al. (2010) demonstrated that guanine deaminase in B. japonicum USDA 110 also showed considerable activity to catalyze ammeline deamination compared with AtzB and related $s$-triazine hydrolases which show almost no activity. The enzyme responsible for the ammeline deamination in strain CDB21 is currently unknown.

The proposed catabolic pathways of co-cultured strains ATD6 and CDB21 are shown in Fig. 5. None of the known genes for $s$-triazine-degrading enzymes, including the melamine-degrading genes trzA and triA (Shao et al. 1995; Seffernick et al. 2001), were detected in strain ATD6. The melamine-deaminating activity of the strain was detected in more than $50 \%$ saturation of ammonium sulfate fraction of the cell extract (data not shown). The enzymatic processes of melamine degradation by strain ATD6 are still being elucidated.

Strain CDB21 required the addition of cyanocobalamine for its growth in a mineral salt medium where simazine was added as a sole carbon and nitrogen source. However, a bacterial consortium containing strains CDB21 and CSB1 was able to grow on mineral salt agar containing simazine without cyanocobalamine (Iwasaki et al. 2007). Therefore, strain CSB1 was expected to enhance melamine degradation by producing essential nutrients for strain CDB21 in the three-membered consortium.

Melamine is a nitrogen rich compound with a carbon to nitrogen ratio ( $\mathrm{C}: \mathrm{N}$ ratio) of 0.43 . In the early stage of melamine degradation by the three-membered consortium, the carbon supply from the melamine was presumed to be insufficient for the melamine catabolism to proceed. To enhance degradation rate of melamine and its intermediates, an additional carbon source was considered to be required even using the bacterial consortium. The utilization of carbon sources was significantly limited in strain CDB21 (Iwasaki et al. 2007), but considerable degradation of cyanuric acid by the strain occurred with the addition of ethanol (data not shown). Consequently, the effect of ethanol on melamine degradation by the consortium was examined in the LMM (Fig. 4). Enhanced degradation of $317.2 \mu \mathrm{M}$ of melamine and its catabolites was observed in an ethanol concentration dependent manner. Cyanuric acid disappeared after 3 days of cultivation with $259 \mu \mathrm{M}$ ethanol, which improves the initial C:N ratio of the culture to 0.66 . Further increases in the cyanuric acid disappearance rate were not achieved when the amount of ethanol was increased to $518 \mu \mathrm{M}$. An approximate 1:1 carbon to nitrogen molar ratio is estimated to be sufficient for the complete degradation of cyanuric acid in LMM culture by the three-membered consortium.

In conclusion, a novel melamine-degrading Nocardioides species, strain ATD6, was isolated from a paddy field soil that was collected near the upland field where strain FJ1117YT originated from (Fujii et al. 2007). Bacteria classified in the genus Nocardioides are widely distributed in various environments such as soil, water,
Fig. 5 Proposed pathway for melamine degradation by the combination of strains ATD6 and CDB21. The catabolic pathways of strains ATD6 and CDB21 are indicated by hollow arrows and solid arrows, respectively. Enzymes responsible for $s$-triazine degradation in strain CDB21 are also indicated near by the solid arrows
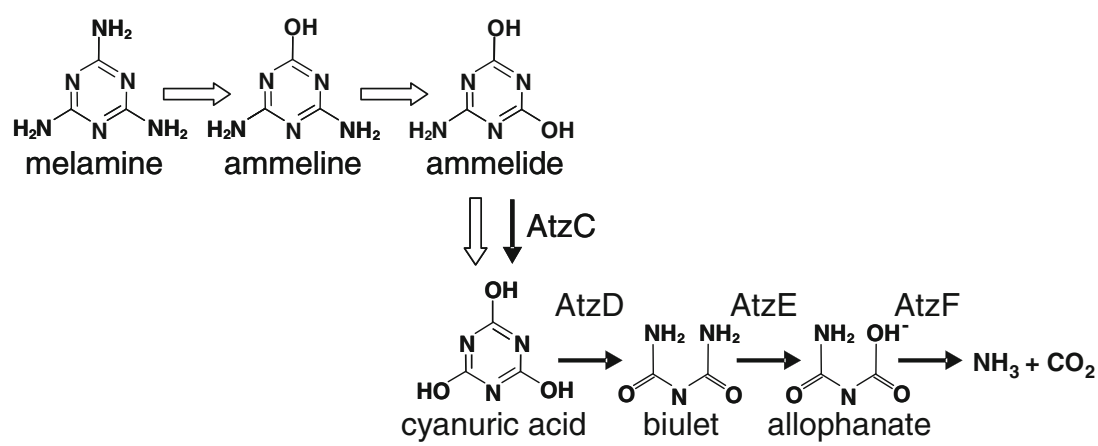
sediment, and sludge. No pathogenicity to plants or animals has currently been reported in any species of the genus Nocardioides. They are often isolated as plant endophytes and are known to be capable of suppressing crop pathogens (Coombs and Franco 2003; Carrer Filho et al. 2008). In comparison with other known melamine-degrading bacteria, strain ATD6 is expected to be the most useful candidate of the tool in the safe bioremediation of a melaminecontaminated farmland. The complete degradation of cyanuric acid, which was formed through melamine catabolism by strain ATD6, was achieved by a consortium containing Methyloversatilis sp. strain CDB21 and B. japonicum strain CSB1. Methyloversatilis belongs to the family Rhodocyclaceae (Kalyuzhnaya et al. 2006), the members of which are widely distributed in the environment. They often prefer oligotrophic conditions and are sometimes identified as plant endophytes. Pathogenic species have not been reported in the Rhodocyclaceae family. B. japonicum is known to be a symbiotic nitrogenfixing bacterium associated with soybeans. Production of rhizobitoxine has been reported by some strains of B. japonicum (Ruan et al. 1993), and the rhizobitoxineproducing capability of strain CSB1 has not yet been examined. Even if the rhizobitoxine gene is detected in strain CSB1, this could be replaced by a nonpathogenic strain of $B$. japonicum or removed from the consortium for use in farmland soil where microbes are abundant. Consequently, the melamine-degrading bacterial consortium used in the current study is also expected to be safely applied to the bioremediation of melamine-contaminated crop fields in preference to the known melamine-degrading bacteria that have been previously reported.

In April 2011, a hydrated lime nitrogen granular fertilizer in which melamine was detected was recalled in Japan (http://in.reuters.com/finance/stocks/4003.T/ key-developments/article/2290868, accessed on July 27, 2011). This contamination of the fertilizer suggests that a wide range of farmland soil in Japan may be contaminated with melamine. The bioremediation of a melaminecontaminated soil by strain ATD6 and the threemembered consortium is currently being investigated.

Acknowledgments The authors are grateful to Ms. Masami Kikuchi for her helpful assistance for the measurement of chemicals.

\section{References}

Audus LJ (1946) A new soil perfusion apparatus. Nature 158:419 Brown CA, Jeong KS, Poppenga RH, Puschner B, Miller DM, Ellis AE, Kang KI, Sum S, Cistola AM, Brown SA (2007) Outbreaks of renal failure associated with melamine and cyanuric acid in dogs and cats in 2004 and 2007. J Vet Diagn Invest 19:525-531
Carrer Filho R, Romeiro RS, Garcia FAO (2008) Biocontrol of foliar disease of tomato plants by Nocardioides thermolilacinus. Trop Plant Patho 33:457-460 (In Portuguese)

Cook AM (1987) Biodegradation of $s$-triazine xenobiotics. FEMS Microbiol Rev 46:93-116

Cook AM, Hütter R (1981) $s$-Triazines as nitrogen sources for bacteria. J Agric Food Chem 29:1135-1143

Cook AM, Hütter R (1984) Deethylsimazine: bacterial dechlorination, deamination, and complete degradation. J Agric Food Chem 32:581-585

Coombs JT, Franco CMM (2003) Isolation and identification of actinobacteria isolated from surface-sterilized wheat roots. Appl Environ Microbiol 69:5603-5608

Dobson RLM, Motlagh S, Quijano M, Cambron RT, Baker TR, Pullen AM, Regg BT, Bigalow-Kern AS, Vennard T, Fix A, Reimschuessel R, Overmann G, Shan Y, Daston GP (2008) Identification and characterization of toxicity of contaminants in pet food leading to an outbreak of renal toxicity in cats and dogs. Toxicol Sci 106:251-262

Eaton RW, Karns JS (1991) Cloning and comparison of the DNA encoding ammelide aminohydrolase and cyanuric acid amidohydrolase from three $s$-triazine-degrading bacterial strains. J Bacteriol 173:1363-1366

El-Sayed WS, El-Baz AF, Othman AM (2006) Biodegradation of melamine formaldehyde by Micrococcus sp. strain MF-1 isolated from aminoplastic wastewater effluent. Int Biodeterior Biodegrad $57: 75-81$

Euzeby JP (1998) Taxonomic note: necessary correction of specific and subspecific epithets according to Rules $12 \mathrm{c}$ and $13 \mathrm{~b}$ of the International Code of Nomenclature of Bacteria (1990 Revision). Int J Syst Bacteriol 48:1073-1075

FAO/WHO (2008) Cyromazine in pesticide residues in food2007 evaluations. Part I-Residues. FAO Plant Production and Protection Paper 192, pp. 253-351. Available at http:// www.fao.org/ag/AGP/AGPP/Pesticid/JMPR/Download/ 2007 eva/Cyromazine.pdf. Accessed 27 July 2011

Fujii K, Takagi K, Hiradate S, Iwasaki A, Harada N (2007) Biodegradation of methylthio-s-triazines by Rhodococcus sp. strain FJ1117YT, and production of the corresponding methylsulfinyl, methylsulfonyl and hydroxy analogues. Pest Manag Sci 63:254-260

Hapeman CJ, Karns JS, Shelton DR (1995) Total mineralization of aqueous atrazine in the presence of ammonium nitrate using ozone and Klebsiella terragena (strain DRS-I): mechanistic considerations for pilot scale disposal. J Agric Food Chem 43:1383-1391

Hart DH, Peel MM, Andrew JH, Burdon JG (1988) Lung infection caused by Rhodococcus. Aust N Z J Med 18:790-791

Iwasaki A, Takagi K, Yoshioka Y, Fujii K, Kojima Y, Harada N (2007) Isolation and characterization of a novel simazinedegrading $\beta$-proteobacterium and detection of genes encoding $s$-triazine-degrading enzymes. Pest Manag Sci 268:261-268

Kalyuzhnaya MG, De Marco P, Bowerman S, Pacheco CC, Lara JC, Lidstrom ME, Chistoserdova L (2006) Methyloversatilis universalis gen. nov., sp. nov., a novel taxon within the Betaproteobacteria represented by three methylotrophic isolates. Int J Syst Evol Microbiol 56:2517-2522

Karns JS (1999) Gene sequence and properties of an $s$-triazine ringcleavage enzyme from Pseudomonas sp. strain NRRLB-12227. Appl Environ Microbiol 65:3512-3517

Lim LO, Scherer SJ, Shuler KD, Toth JP (1990) Disposition of cyromazine in plants under environmental conditions. J Agric Food Chem 38:860-864

Lipschitz WL, Stokey E (1945) The mode of action of three diuretics: melamine, adenine and formoguanamine. J Pharmacol Exp Ther $83: 235-249$ 
Liu JM, Ren A, Yang L, Gao J, Pei L, Ye R, Qu Q, Zheng X (2010) Urinary tract abnormalities in Chinese rural children who consumed melamine-contaminated dairy products: a populationbased screening and follow-up study. Can Med Assoc J 182:439443

Martinez B, Tomkins J, Wackett LP, Wing R, Sadowsky MJ (2001) Complete nucleotide sequence and organization of the atrazine catabolic plasmid pADP-1 from Pseudomonas sp. strain ADP. J Bacteriol 183:5684-5697

Mordarski M, Goodfellow M, Kaszen I, Tkacz A, Pulverer G, Schaal KP (1980) Deoxyribonucleic acid reassociation in the classification of the genus Rhodococcus Zopf 1891 (Approved Lists, 1980). Int J Syst Bacteriol 30:521-527

Osoagbaka OU (1989) Evidence for the pathogenic role of Rhodococcus species in pulmonary disease. J Appl Bacteriol 66:497-506

Peacock CH, Dipaola JM (1992) Turf response to triazine carriers as influenced by Pseudomonas inoculant. Agron J 84:583-585

Prauser H (1976) Nocardioides, a new genus of the order Actinomycetales. Int J Syst Bacteriol 26:58-65

Qin Y, Lv X, Li J, Qi G, Diao Q, Liu G, Xue M, Wang J, Tong J, Zhang L, Zhang K (2010) Assessment of melamine contamination in crop, soil and water in China and risks of melamine accumulation in animal tissues and products. Environ Int 36:446452

Ruan X, Zhang C, Peters NK (1993) Bradyrhizobium japonicum rhizobitoxine genes and putative enzyme functions: expression requires a translational frameshift. Proc Natl Acad Sci U S A 90:2641-2645

Sancho V, Ibáñez M, Grimalt S, Pozo ÓJ, Hernández F (2005) Residue determination of cyromazine and its metabolite melamine in chard samples by ion-pair liquid chromatography coupled to electrospray tandem mass spectrometry. Anal Chim Acta 530:237-243

Schaad NW, Postnikova E, Sechler A, Claflin LE, Vidaver AK, Jones JB, Agarkova I, Ignatov A, Dickstein E, Ramundo BA (2008) Reclassification of subspecies of Acidovorax avenae as A. avenae (Manns 1905) emend., A. cattleyae (Pavarino, 1911) comb. nov., A. citrulli (Schaad et al., 1978) comb. nov., and proposal of A. oryzae sp. nov. Syst Appl Microbiol 31:434-446

Scholl W, Davis ROE, Brown EE, Reid FR (1937) Melamine of possible plant food value. Ind Eng Chem 29:202-205

Seffernick JL, De Souza ML, Sadowsky MJ, Wackett LP (2001) Melamine deaminase and atrazine chlorohydrolase: 98 percent identical but functionally different. J Bacteriol 183:2405-2410

Seffernick JL, Shapir N, Schoeb M, Johnson G, Sadowsky MJ, Wackett LP (2002) Enzymatic degradation of chlorodiamino-striazine. Appl Environ Microbiol 68:4672-4675

Seffernick JL, Dodge AG, Sadowsky MJ, Bumpus JA, Wackett LP (2010) Bacterial ammeline metabolism via guanine deaminase. J Bacteriol 192:1106-1112

Shao ZQ, Seffens W, Mulbry W, Behki RM (1995) Cloning and expression of the $s$-triazine hydrolase gene $(\operatorname{trz} A)$ from Rhodococcus corallinus and development of Rhodococcus recombinant strains capable of dealkylating and dechlorinating the herbicide atrazine. J Bacteriol 177:5748-5755

Shapir N, Osborne JP, Johnson G, Sadowsky MJ, Wackett LP (2002) Purification, substrate range, and metal center of AtzC: the $n$ - isopropylammelide aminohydrolase involved in bacterial atrazine metabolism. J Bacteriol 184:5376-5384

Shapir N, Cheng G, Sadowsky MJ, Wackett LP (2006) Purification and characterization of TrzF: biuret hydrolysis by allophanate hydrolase supports growth. Appl Environ Microbiol 72:2491-2495

Shelton DR, Karns JS, Mccarty GW, Durham DR (1997) Metabolism of melamine by Klebsiella terragena. Appl Environ Microbiol 63:2832-2835

Stackebrandt E, Smida J, Collins MD (1988) Evidence of phylogenetic heterogeneity within the genus Rhodococcus: revival of the genus Gordona (Tsukamura). J Gen Appl Microbiol 34:341-348

Suchý P, Straková E, Herzig I, Staňa J, Kalusová R, Pospíchalová M (2009) Toxicological risk of melamine and cyanuric acid in food and feed. Interdiscip Toxicol 2:55-59

Sun Q, Shen Y, Sun N, Zhang GJ, Chen Z, Fan JF, Jia LQ, Xiao HZ, Li XR, Puschner B (2010) Diagnosis, treatment and follow-up of 25 patients with melamine-induced kidney stones complicated by acute obstructive renal failure in Beijing Children's Hospital. Eur J Pediatr 169:483-489

Takagi K, Iwasaki A, Kamei I, Satsuma K, Yoshioka Y, Harada N (2009) Aerobic mineralization of hexachlorobenzene by newly isolated pentachloronitrobenzene-degrading Nocardioides sp. strain PD653. Appl Environ Microbiol 75:44524458

Terman GL, DeMent JD, Hunt CM, Cope JT Jr, Ensminger LE (1964) Crop response to urea and urea pyrolysis products. J Agric Food Chem 12:151-154

Thompson JD, Gibson TJ, Plewniak F, Jeanmougin F, Higgins DG (1997) The CLUSTAL X windows interface: flexible strategies for multiple sequence alignment aided by quality analysis tools. Nucleic Acids Res 25:4876-4882

Valdivia-Arenas MA, Sood N (2008) Micrococcus bloodstream infection in patients with pulmonary hypertension on epoprostenol. Infect Dis Clin Pract 16:285-287

Wehner DJ, Martin DL (1989) Melamine/urea and oxamide fertilization of Kentucky bluegrass. Commun Soil Sci Plant Anal 20:1659-1673

WHO (2009) Toxicological and health aspects of melamine and cyanuric acid. WHO web. Available at http://whqlibdoc.who.int/publications/ 2009/9789241597951_eng.pdf. Accessed 27 July 2011

Yamazaki K, Fujii K, Iwasaki A, Takagi K, Satsuma K, Harada N, Uchiyama T (2008a) Different substrate specificities of two triazine hydrolases (TrzNs) from Nocardioides species. FEMS Microbiol Lett 286:171-177

Yamazaki K, Takagi K, Fujii K, Iwasaki A, Harada N, Uchiyama T (2008b) Simultaneous biodegradation of chloro- and methylthios-triazines using charcoal enriched with a newly developed bacterial consortium. J Pest Sci 33:266-270

Yanze-kontchou C, Gschwind N (1994) Mineralization of the herbicide atrazine as by a Pseudomonas strain. Appl Environ Microbiol 60:4297-4302

Yoon JH, Lee ST, Park YH (1998) Inter- and intraspecific phylogenetic analysis of the genus Nocardioides and related taxa based on 16S rDNA sequences. Int J Syst Bacteriol 48:187-194

Yoon JH, Cho YG, Lee ST, Suzuki K, Nakase T, Park YH (1999) Nocardioides nitrophenolicus sp. nov., a $p$-nitrophenol-degrading bacterium. Int J Syst Bacteriol 49:675-680 